\title{
Antimicrobial Activity of Brown Alga Eisenia bicyclis against Methicillin-resistant Staphylococcus aureus
}

\author{
Sung-Hwan Eom ${ }^{1}$, Jae-Hong Park ${ }^{1}$, Dae-Ung Yu ${ }^{1}$, Ji-Il Choi ${ }^{1}$, Jong-Duck Choi ${ }^{2,3}$, Myung-Suk Lee ${ }^{4}$ and \\ Young-Mog $\mathrm{Kim}^{1 *}$ \\ ${ }^{1}$ Department of Food Science and Technology, Pukyong National University, Busan 608-737, Korea \\ ${ }^{2}$ Department of Seafood Science and Technology, Gyeongsang National University, Tongyeong 650-160, Korea \\ ${ }^{3}$ Institute of Marine Industry, Gyeongsang National University, Tongyeong 650-160, Korea \\ ${ }^{4}$ Department of Microbiology, Pukyong National University, Busan 608-737, Korea
}

\begin{abstract}
We screened for antibacterial substances against methicillin-resistant Staphylococcus aureus (MRSA). Methanolic extract of Eisenia bicyclis exhibited anti-MRSA activity according to a disk diffusion assay. To identify the active compound(s), the methanolic extract was further fractionated using hexane, dichloromethane, ethyl acetate, and $n$-butanol. The ethyl acetate-soluble fraction showed both the greatest anti-MRSA activity and the highest polyphenol content. The minimum inhibitory concentrations of the ethyl acetate fraction ranged from 32 to $64 \mu \mathrm{g}$ per mL against methicillin-susceptible $S$. aureus and MRSA strains. High-performance liquid chromatography analysis revealed that both the methanolic extract and the ethyl acetate soluble fraction contained sizeable quantities of dieckol, which is a known anti-MRSA compound. Thus, these data strongly suggest that the anti-MRSA activity of E. bicyclis may be mediated by phlorotannins such as dieckol.
\end{abstract}

Key words: Anti-MRSA activity, Eisenia bicyclis, Methicillin-resistant Staphylococcus aureus

\section{Introduction}

Since methicillin was introduced in 1959 to resolve infections caused by penicillin-resistant Staphylococcus aureus, the incidence of methicillin resistance in staphylococci has increased rapidly (Kaplan, 2005). As a result of widespread methicillin use, methicillin-resistant $S$. aureus (MRSA) has become a major problem globally (Lee et al., 2008). MRSA infections are difficult to treat because of the multidrug-resistance properties of MRSA, which is resistant to $\beta$-lactams as well as several other classes of antibiotics (Bramley et al., 1989; Hiramatsu et al., 1997). Vancomycin is commonly used for the treatment of MRSA-related infection. Vancomycin resistance was discovered first in enterococci and later in staphylococci (Isnansetyo and Kamei, 2009). The emergence of vancomycin-resistant $S$. aureus has recently been recog- nized and leaves physicians with few options available to treat MRSA infections. Therefore, much attention has been given to the search for new antimicrobial agents (Lee et al., 2008).

In an effort to decrease usage of vancomycin and discover an alternative therapeutic agent for treating MRSA infection, we have screened marine algae for anti-MRSA compounds. Eisenia bicyclis is a common perennial phaeophyceae (brown alga) that generally inhabits the coast of Ulleung Island in the East Sea of Korea. This seaweed is used in various dishes, including appetizers, casseroles, muffins, pilafs, and soups (Eom et al., 2011; Kim et al., 2011). The antioxidant activity of E. bicyclis phlorotannins such as eckol (a trimer), phlorofucofuroeckol A (a pentamer), dieckol, and 8,8'-bieckol (hexamers) has been reported (Okada et al., 2004). This brown algae
Open Access http://dx.doi.org/10.5657/FAS.2011.0251

This is an Open Access article distributed under the terms of the Creative Commons Attribution Non-Commercial License (http://creativecommons. org/licenses/by-nc/3.0/) which permits unrestricted non-commercial use, distribution, and reproduction in any medium, provided the original work is properly cited. pISSN: 2234-1749 eISSN: 2234-1757
Received 17 August 2011; Accepted 28 October 2011

*Corresponding Author

E-mail: ymkim@pknu.ac.kr 
also exhibits activity against tumors (Noda et al., 1989), Alzheimer's disease (Jung et al., 2010), atherosclerosis (Kang et al., 2003), inflammatory diseases (Shibata et al., 2003), allergic disease, and cancer (Shibata et al., 2002). However, to our knowledge, no study has reported on the antimicrobial activity of E. bicyclis. Here, we examined the antibacterial activity of E. bicyclis against several pathogenic bacteria, including MRSA.

\section{Materials and Methods}

\section{Raw materials and extraction}

In late September 2010, the brown seaweed E. bicyclis was gathered from Ulleung Island, Korea. Dried E. bicyclis was ground and then finely powdered using a food mixer (HMF1000A; Hanil Electronics, Seoul, Korea). The dried powder was stored at $-20^{\circ} \mathrm{C}$ until required. Powdered E. bicyclis (1 $\mathrm{kg}$ ) was extracted with methanol $(3$ times $\times 10 \mathrm{~L}$ ) for $3 \mathrm{~h}$. The combined filtrate was concentrated by rotary evaporation at $40^{\circ} \mathrm{C}$. After suspending in water $(1 \mathrm{~L})$, the methanol extract was partitioned with $n$-hexane (hexane), dichloromethane (DCM), ethyl acetate (EtOAc), and $n$-butanol (BuOH), in sequence.

\section{Microorganisms and culture}

Standard bacterial strains were obtained from the Korean Collection of Type Cultures (KCTC; Daejeon, Korea) and the Korean Culture Center of Microorganisms (KCCM; Seoul, Korea). The bacterial strains used were methicillinsusceptible S. aureus (MSSA; KCTC 1927), two MRSA strains (MRSA; KCCM 40510 and KCCM 40511), Bacillus cereus (KCTC 3624), B. subtilis (KCTC 1028), Enterococcus faecalis (KCTC 3206), Escherichia coli (KCTC 1682), Listeria monocytogenes (KCTC 3710), Salmonella typhimurium (KCTC 1925), and Vibrio parahaemolyticus (KCTC 2729). All strains were grown aerobically at $37^{\circ} \mathrm{C}$ in Mueller-Hinton broth (MHB; Difco, Detroit, MI, USA) or tryptic soy broth (TSB; Difco) for determination of the minimum inhibitory concentration (MIC) and in Mueller-Hinton agar (MHA; Difco) for disk diffusion and minimum bactericidal concentration (MBC) assays.

\section{Disk diffusion assays}

Antibacterial activity was evaluated by a disk diffusion assay, as described by the National Committee for Clinical Laboratory Standards (National Committee for Clinical Laboratory Standards, 2004). In brief, bacterial strains were cultured in TSB at $37^{\circ} \mathrm{C}$ until an $\mathrm{OD}_{600}$ of 0.5 . Bacterial culture $(1 \mathrm{~mL})$, containing approximately $10^{4} \mathrm{CFU}$, was spread on a MHA plate, and a paper disk (6 $\mathrm{mm}$ diameter) containing 1 mg extract was then placed on the agar surface. After incubation for $24 \mathrm{~h}$ at $37^{\circ} \mathrm{C}$, the diameter of the inhibition zone was measured. The determination was performed three times and the mean values presented.

\section{Minimum inhibitory concentrations (MIC)}

The MIC is the lowest concentration of antimicrobials that will inhibit the visible growth of microorganisms after overnight incubation (Grierson and Afolayan, 1999). MICs of the extracts and vancomycin were determined by the twofold serial dilution method in MHB (NCCLS, 2003). MIC was defined as the lowest concentration of crude extract that inhibited visual growth after incubation at $37^{\circ} \mathrm{C}$ for $20-24 \mathrm{~h}$, and was performed in triplicate (Grierson and Afolayan, 1999).

\section{Minimum bactericidal concentrations (MBC)}

The MBC value was defined as the lowest concentration of E. bicyclis extracts required for a $99.9 \%$ reduction in the viable cell population (Shen et al., 2002; NCCLS, 2003). For determining $\mathrm{MBC}$ values, an aliquot $(0.1 \mathrm{~mL})$ of MIC mixtures that showed no growth was inoculated onto MHA plates and incubated at $35^{\circ} \mathrm{C}$ for $48 \mathrm{~h}$ (Syu et al., 2004).

\section{High-performance liquid chromatography}

To identify the active compound(s) in E. bicyclis extracts, high-performance liquid chromatography (HPLC) was performed using a Hitachi 2000 series HPLC system (Hitachi Tech, Tokyo, Japan) equipped with Shiseido $\mathrm{C}_{18}$ reverse-phase column (250 mm $\times 4.6 \mathrm{~mm}$, I.D. $5 \mu \mathrm{m}$; Shiseido Co., Tokyo, Japan). For detection of the bioactive substance, a linear gradient elution of $90 \%$ water with 10 to $100 \%$ (v/v) methanol was used at a flow rate of $1.0 \mathrm{~mL}$ per min for $45 \mathrm{~min}$. Eluates were monitored at $230 \mathrm{~nm}$.

Standard phlorotannins (dieckol, eckol, and eckstolonol) were used to allow quantification. Standard compound concentrations were calculated in the range of 0.01 to $0.1 \mathrm{mg}$ by linear regression from the respective calibration curves. Eckol $\left(\mathrm{Y}=12.973 \mathrm{X}-0.4261 ;-r^{2}=0.9991\right)$, dieckol $(\mathrm{Y}=17.065 \mathrm{X}+$ $\left.1.3499 ;-r^{2}=0.9993\right)$, and eckstolonol $(\mathrm{Y}=10.192 \mathrm{X}+0.7048$; $\left.-r^{2}=0.9963\right)$ standard curves were obtained (data not shown).

\section{Results and Discussion}

\section{Anti-MRSA activity of $E$. bicyclis extract}

E. bicyclis methanolic extract exhibited anti-MRSA activity, suggesting the presence of an antibacterial substance (Table 1). Also, the extract exhibited similar activity against MSSA (Table 1). To identify the antimicrobial substance, the extract was further fractionated using organic solvents. Lyophilized 
E. bicyclis extract $(1.0 \mathrm{~kg})$ was percolated in methanol (3 times $\times 1,000 \mathrm{~mL}$ ), followed by fractionation with organic solvents to yield hexane- (0.05 g), DCM- (0.05 g), EtOAc- (0.11 $\mathrm{g}), \mathrm{BuOH}$ ion- $(0.39 \mathrm{~g})$, and water-soluble $(0.57 \mathrm{~g})$ fractions. The anti-MRSA activity of the hexane, DCM, EtOAc, BuOH, and water-soluble fractions was evaluated by measuring the inhibition zones. Of these, the EtOAc-soluble fraction showed the strongest anti-MRSA activity, followed by $\mathrm{DCM}, \mathrm{BuOH}$, and hexane, in that order (Table 1). No anti-MRSA activity was detected in the water-soluble fraction. These results were consistent with the reports of Lee et al. (2008) and Choi et al. (2010) stating that the EtOAc-soluble fraction of Ecklonia stolonifera and Ecklonia cava exhibited the strongest antiMRSA activity. The antibacterial substance was subsequently identified.

\section{Determination of the MIC and MBC of E. bicyclis extract}

The current study focused on the antibacterial activity of E. bicyclis extracts against MRSA. To quantitatively evaluate this antibacterial activity, we investigated the MIC and MBC values of the extract (Table 2). The highest anti-MRSA and MSSA activities were present in the EtOAc-soluble fraction at 32-64 $\mu \mathrm{g} / \mathrm{mL}$. These results were consistent with those of the disk diffusion assay. The MICs and MBCs of the methanolic extract against MSSA and MRSA ranged from 64 to $256 \mu \mathrm{g} /$ $\mathrm{mL}$; those of the other fractions (hexane, DCM and $\mathrm{BuOH}$ ) were between 32 and $64 \mu \mathrm{g} / \mathrm{mL}$ for MICs and 64 and $256 \mu \mathrm{g} /$ $\mathrm{mL}$ for MBCs. However, no antibacterial activity was detected in the water-soluble fraction (Table 2). These results strongly suggest the presence of an anti-MRSA compound in the EtOAc-soluble fraction of the E. bicyclis methanolic extract.

Kim et al. (2002) reported that the EtOAc extract of this seaweed showed the highest antibacterial activity against the cavity-causing Gram-positive bacterium Streptococcus mutans. Therefore, we investigated the antibacterial activity of $E$.

Table 1. Growth inhibitory of Eisenia bicyclis extracts against methicillin-resistant Staphylococcus aureus (MRSA) and other strains

\begin{tabular}{cccccccc}
\hline \multirow{2}{*}{ Strains } & Concentration & \multicolumn{5}{c}{ Zone of inhibition (mm) } \\
\cline { 3 - 7 } & & MeOH & Hexane & DCM & EtOAc & BuOH & H $\mathbf{O}^{-}$ \\
\hline Staphylococcus aureus (KCTC 1927) & $1 \mathrm{mg} /$ disk & $10.0^{*}$ & 10.5 & 10.0 & 15.0 & 9.5 & - \\
MRSA (KCCM40510) & $1 \mathrm{mg} /$ disk & 13.5 & 10.0 & 15.5 & 17.0 & 10.0 & - \\
MRSA (KCCM40511) & $1 \mathrm{mg} /$ disk & 11.0 & 9.0 & 11.0 & 16.0 & 10.0 & - \\
\hline
\end{tabular}

Each extract of Eisenia bicyclis was loaded onto a disk (6 $\mathrm{mm}$ in diameter).

$\mathrm{MeOH}$, methanolic extract; DCM, dichloromethane soluble fraction; EtOAc, ethyl acetate souble fraction; $\mathrm{BuOH}$, butanol soluble fraction; $\mathrm{H}_{2} \mathrm{O}$, water soluble fraction; -, no growth inhibition.

"Data are the averages of triplicate experiments.

Table 2. Minimum inhibitory concentrations (MICs) and minimum bactericidal concentrations (MBCs) of Eisenia bicyclis extracts against methicillinresistant Staphylococcus aureus (MRSA) and other strains

\begin{tabular}{|c|c|c|c|c|c|c|c|c|c|c|c|c|c|c|}
\hline \multirow{2}{*}{ Strains } & \multicolumn{2}{|c|}{ МeOH } & \multicolumn{2}{|c|}{ Hexane } & \multicolumn{2}{|c|}{ DCM } & \multicolumn{2}{|c|}{ EtOAc } & \multicolumn{2}{|c|}{$\mathrm{BuOH}$} & \multicolumn{2}{|c|}{$\mathrm{H}_{2} \mathrm{O}$} & \multicolumn{2}{|c|}{ Vancomycin } \\
\hline & MIC & $\overline{\mathrm{MBC}}$ & MIC & $\overline{\mathrm{MBC}}$ & $\overline{\mathrm{MIC}}$ & $\overline{\text { MBC }}$ & MIC & $\overline{\text { MBC }}$ & MIC & MBC & MIC & MBC & MIC & MBC \\
\hline \multicolumn{15}{|l|}{ Gram-positive bacteria } \\
\hline MRSA (KCCM 40510) & 64 & 64 & 64 & 64 & 128 & 128 & 32 & 64 & 128 & 256 & $>512$ & $>512$ & 2 & 4 \\
\hline MRSA (KCCM 40511) & 128 & 128 & 128 & 128 & 128 & 128 & 64 & 64 & 128 & 128 & $>512$ & $>512$ & 2 & 4 \\
\hline Staphylococcus aureus (KCTC 1927) & 128 & 256 & 128 & 128 & 64 & 128 & 32 & 32 & 128 & 128 & $>512$ & $>512$ & 0.5 & 1 \\
\hline Bacillus cereus (ATCC 14579) & 256 & 256 & 32 & 64 & 32 & 64 & 32 & 32 & 64 & 64 & 512 & $>512$ & 1 & 2 \\
\hline Bacillus subtilis (KCTC 1028) & 128 & 128 & 64 & 64 & 64 & 64 & 32 & 32 & 128 & 128 & 256 & 512 & 0.5 & 1 \\
\hline Listeria monocytogenes (KCTC 3710) & 256 & 256 & 256 & 256 & 128 & 128 & 64 & 64 & 256 & 256 & $>512$ & $>512$ & 1 & 4 \\
\hline Enterococcus faecalis (KCTC 3206) & 512 & 512 & 512 & 512 & 256 & 512 & 64 & 128 & 512 & $>512$ & $>512$ & $>512$ & 1 & 4 \\
\hline \multicolumn{15}{|l|}{ Gram-negative bacteria } \\
\hline Escherichia coli (KCTC 1682) & 256 & 256 & 512 & 512 & 256 & 256 & 128 & 256 & 512 & $>512$ & $>512$ & $>512$ & 512 & $>512$ \\
\hline Salmonella typhimurium (КCTC 1925) & 256 & 512 & 512 & 512 & 64 & 128 & 32 & 64 & 256 & 512 & $>512$ & $>512$ & 512 & $>512$ \\
\hline Vibrio parahaemolyticus (KCTC 2729) & 128 & 128 & 128 & 128 & 32 & 32 & 32 & 32 & 128 & 128 & $>512$ & $>512$ & 256 & $>512$ \\
\hline
\end{tabular}

Values are presented as $\mu \mathrm{g} / \mathrm{mL}$. $\mathrm{MeOH}$, methanolic extract; $\mathrm{DCM}$, dichloromethane soluble fraction.; EtOAc, ethyl acetate soluble fraction; BuOH, butanol soluble fraction; $\mathrm{H}_{2} \mathrm{O}$, water soluble fraction.

"Data are the averages of triplicate experiments. 
bicyclis extract against several pathogenic and spoilage bacteria (Table 2). The EtOAc fraction showed the highest antibacterial activity against these bacterial strains. The MICs and MBCs of the EtOAc fraction were $32-256 \mu \mathrm{g} / \mathrm{mL}$.

Vancomycin, a tricyclic glycopeptide antibiotic, is used to treat MRSA infections (Lee et al., 2008). Vancomycin interferes with bacterial cell wall synthesis, as does penicillin, eventually leading to cell lysis (Barna and Williams, 1984). Most Gram-negative bacteria are less sensitive to vancomycin than Gram-positives (Totsuka et al., 1999; Lee et al., 2008). As expected, the MICs of vancomycin against Gram-negative bacteria were over $512 \mu \mathrm{g} / \mathrm{mL}$ compared to $0.5-4 \mu \mathrm{g} /$ $\mathrm{mL}$ against Gram-positives (Table 2). Unlike vancomycin, the EtOAc fraction exhibited strong antibacterial activity (MICs 32-128 $\mu \mathrm{g} / \mathrm{mL}$; MBCs 32-256 $\mu \mathrm{g} / \mathrm{mL}$ ) against Gram-negative bacteria. These data suggest the existence of different mechanisms of inhibiting cell growth and bacterial cell wall synthesis.

\section{Identification of an anti-MRSA substance from $E$. bicyclis}

The biological activities of plant materials are related to their phenolic compound content (Kim et al., 2006; Lin et al., 2008). Such activity is based on the physiological functions of polyphenol polymers (McDougall et al., 2005). Seaweed polyphenol (phlorotannin) is the predominant EtOAc-soluble compound in brown algae (Lee et al., 2008; Choi et al., 2010). Phloroglucinols, such as eckol, phlorofucofuroeckol-A, diek- col, and 8,8'-bieckol, also exhibit antibacterial activity (Isnansetyo et al., 2001; Nagayama et al., 2002).

We detected anti-MRSA activity in E. bicyclis methanolic extract. Additionally, the ethyl acetate-soluble fraction exhibited the highest antibacterial activity against other pathogenic bacteria, suggesting that the antibacterial compound is abundant in the EtOAc fraction (Table 2). To identify the active compound, we conducted HPLC analysis (Figs. 1 and 2). Purified phloroglucinol compounds (dieckol, eckol, and eckstolonol) were used as controls. Identification of unknown phloroglucinol compounds was achieved by comparing retention time with those of control compounds. The retention times of dieckol, eckol, and eckstolonol were $12.98 \pm 0.30,10.87 \pm$ 0.29 , and $21.52 \pm 0.45 \mathrm{~min}$, respectively (Fig. 1). HPLC analysis showed that only the methanolic extract and the EtOAc-

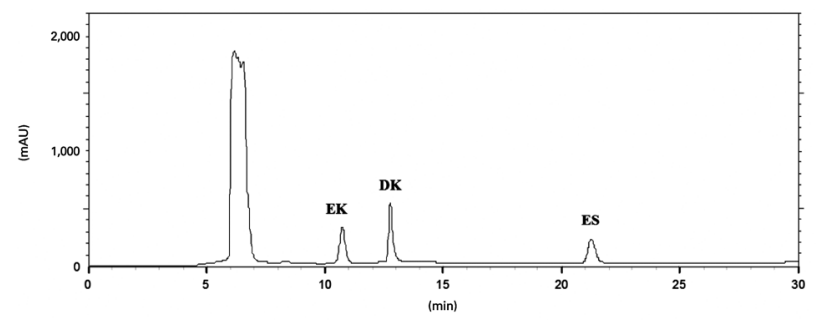

Fig. 1. High-performance liquid chromatography (HPLC) profile of standard phlorotannins. HPLC analysis was performed as described in Materials and Methods. EK, $100 \mu \mathrm{g}$ per $\mathrm{mL}$ of eckol; DK, $100 \mu \mathrm{g}$ per $\mathrm{mL}$ of dieckol; ES, $100 \mu \mathrm{g}$ per $\mathrm{mL}$ of eckstolonol.
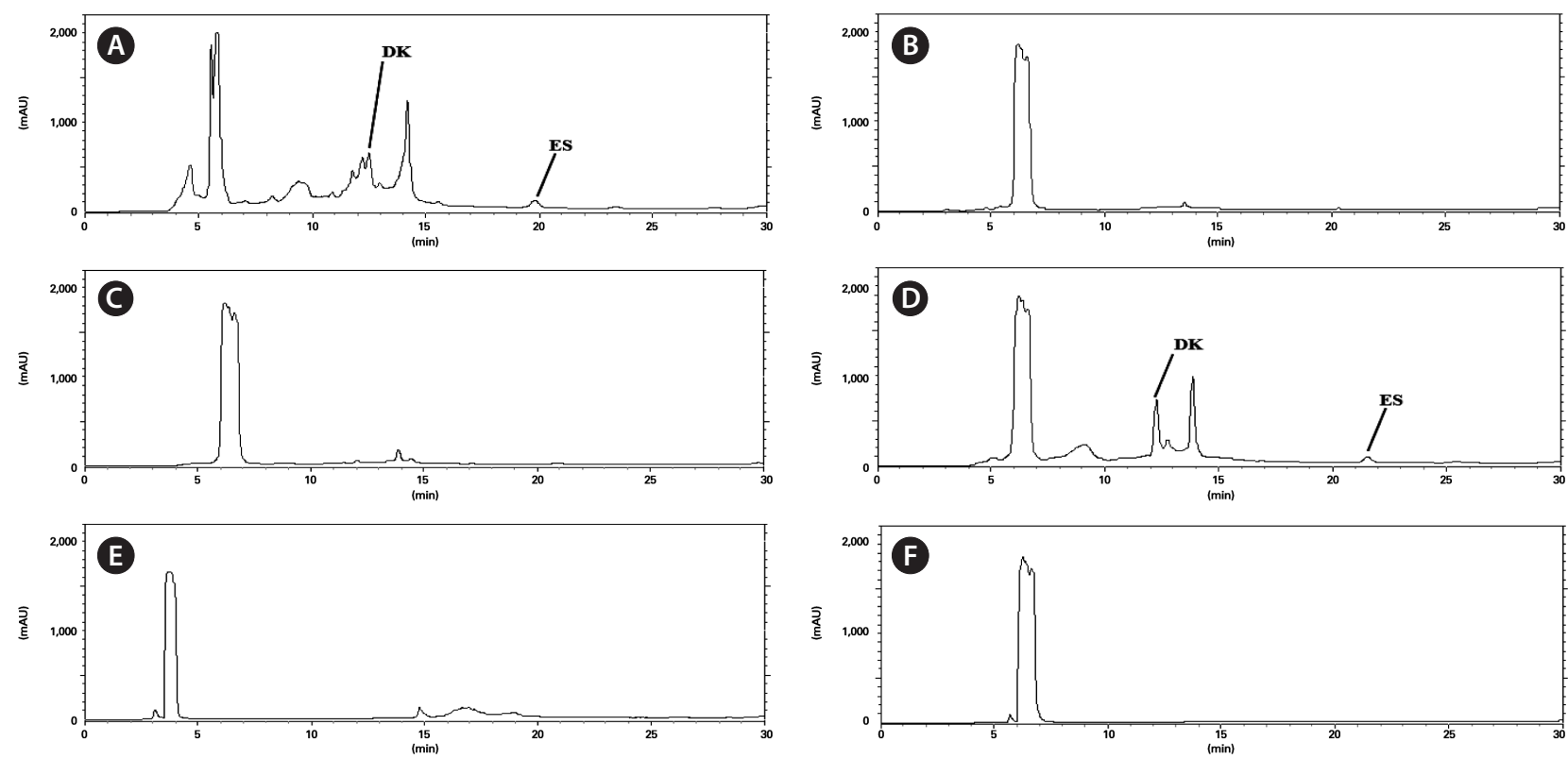

Fig. 2. HPLC profiles of Eisenia bicyclis extracts after 5 days of fermentation. A, B, C, D, E and F are the HPLC profiles for methanol extract, $n$-hexane-soluble extract, dichloromethane-soluble extract, ethyl acetate-soluble extract, $n$-butanol-soluble extract, water-soluble extract. The injection amount was 1,000 ppm. 
soluble fraction contained sizeable quantities of dieckol (76.9 $\mathrm{mg} / \mathrm{g}$ in the EtOAc-soluble fraction) (Table 2).

Dieckol is a known antibacterial substance with activity against MRSA (Lee et al., 2008). Of the soluble fractions, dieckol was present only in the EtOAc fraction, which exhibited the highest anti-MRSA activity. Our previous report showed that of the pholorotannins tested, dieckol showed the highest anti-MRSA activity (Lee et al., 2008). Considering these data, we suggest that the anti-MRSA activity of E. bicyclis is likely mediated by phlorotannins such as dieckol.

\section{Acknowledgments}

This research was supported by the special fund of Pukyong National University donated by the SKS Trading Co. in Lynnwood, Washington, U.S.A. in memory of late Mr. YoungHwan Kang, who had a deep concerns and inspiration in fishery science.

\section{References}

Barna JCJ and Williams DH. 1984. The structure and mode of action of glycopeptide antibiotics of the vancomycin group. Annu Rev Microbiol 38, 339-357.

Bramley AJ, Patel AH, O'Reilly M, Foster R and Foster TJ. 1989. Roles of alpha-toxin and beta-toxin in virulence of Staphylococcus aureus for the mouse mammary gland. Infect Immun 57, 2489-2494.

Choi JG, Kang OH, Brice OO, Lee YS, Chae HS, Oh YC, Sohn DH, Park H, Choi HG, Kim SG, Shin DW and Kwon DY. 2010. Antibacterial activity of Ecklonia cava against methicillin-resistant Staphylococcus aureus and Salmonella spp. Foodborne Pathog Dis 7, 435-441.

Eom SH, Kang YM, Park JH, Yu DU, Jeong ET, Lee MS and Kim YM. 2011. Enhancement of polyphenol content and antioxidant activity of Eisenia bicyclis extract by microbial fermentation. Fish Aquat Sci 14, 192-197.

Grierson DS and Afolayan AJ. 1999. Antibacterial activity of some indigenous plants used for the treatment of wounds in the Eastern Cape, South Africa. J Ethnopharmacol 66, 103-106.

Hiramatsu K, Hanaki H, Ino T, Yabuta K, Oguri T and Tenover FC. 1997. Methicillin-resistant Staphylococcus aureus clinical strain with reduced vancomycin susceptibility. J Antimicrob Chemother 40, 135-136.

Isnansetyo A and Kamei Y. 2009. Anti-methicillin-resistant Staphylococcus aureus (MRSA) activity of MC21-B, an antibacterial compound produced by the marine bacterium Pseudoalteromonas phenolica $\mathrm{O}-\mathrm{BC} 30^{\mathrm{T}}$. Int J Antimicrob Agents 34, 131-135.

Isnansetyo A, Horikawa M, and Kamei Y. 2001. In vitro anti-methicillin-resistant Staphylococcus aureus activity of 2,4-diacetylphloroglucinol produced by Pseudomonas sp. AMSN isolated from a marine alga. J Antimicrob Chemother 47, 724-725.

Jung HA, Oh SH and Choi JS. 2010. Molecular docking studies of phlo- rotannins from Eisenia bicyclis with BACE1 inhibitory activity. Bioorg Med Chem Lett 20, 3211-3215.

Kang K, Park Y, Hwang HJ, Kim SH, Lee JG and Shin HC. 2003. Antioxidative properties of brown algae polyphenolics and their perspectives as chemopreventive agent against vascular risk factors. Arch Pharm Res 26, 286-293.

Kaplan SL. 2005. Implications of methicillin-resistant Staphylococcus aureus as a community-acquired pathogen in pediatric patients. Infect Dis Clin N Am 19, 747-757.

Kim JH, Lee DS, Lim CW, Park HY and Park JH. 2002. Antibacterial activity of sea-mustard, Laminaria japonica extracts on the cariogenic bacteria, Streptococcus mutans. J Korean Fish Soc 35, 191-195.

Kim SM, Shang YF and Um BH. 2011. A preparative method for isolation of fucoxanthin from Eisenia bicyclis by centrifugal partition chromatography. Phytochem Anal 22, 322-329.

Kim MM, Ta QV, Mendis E, Rajapakse N, Jung WK, Byun HG, Jeon YJ and Kim SK. 2006. Phlorotannins in Ecklonia cava extract inhibit matrix metalloproteinase activity. Life Sci 79, 1436-1443.

Lee DS, Kang MS, Hwang HJ, Eom SH, Yang JY, Lee MS, Lee WJ, Jeon YJ, Choi JS and Kim YM 2008. Synergistic effect between dieckol from Ecklonia stolonifera and $\beta$-lactams against methicillin-resistant Staphylococcus aureus. Biotechnol Bioprocess Eng 13, 758-764.

Lin RD, Chin YP, Hou WC and Lee MH. 2008. The effects of antibiotics combined with natural polyphenols against clinical methicillinresistant Staphylococcus aureus (MRSA). Planta Med 74, 840-846.

McDougall GJ, Shpiro F, Dobson P, Smith P, Blake A and Stewart D. 2005. Different polyphenolic components of soft fruits inhibit alpha-amylase and alpha-glucosidase. J Agric Food Chem 53, 27602766.

Nagayama K, Iwamura Y, Shibata T, Hirayama I and Nakamura T. 2002. Bactericidal activity of phlorotannins from the brown alga Ecklonia kurome. J Antimicrob Chemother 50, 889-893.

National Committee for Clinical Laboratory Standards (NCCLS). 2003. Methods for Dilution Antimicrobial Susceptibility Tests for Bacteria That Grow Aerobically: Approved Standard. 6th ed. NCCLS Document M7-A6. NCCLS, Wayne, PA, US.

National Committee for Clinical Laboratory Standards (NCCLS). 2004. Performance Standards for Antimicrobial Disk Susceptibility Testing. 14th Informational Supplement. NCCLS Document M100514. NCCLS, Wayne, PA, US.

Noda H, Amano H, Arashima K, Hashimoto S and Nisizawa K. 1989. Studies on the antitumour activity of marine algae. Nippon Suisan Gakkaishi 55, 1259-1264.

Okada Y, Ishimaru A, Suzuki R and Okuyama T. 2004. A new phloroglucinol derivative from the brown alga Eisenia bicyclis: potential for the effective treatment of diabetic complications. J Nat Prod 67, 103-105.

Shen CC, Syu WJ, Li SY, Lin CH, Lee GH and Sun CM. 2002. Antimicrobial activities of Naphthazarins from Arnebia euchroma. J Nat Prod 65, 1857-1862.

Shibata T, Fujimoto K, Nagayama K, Yamaguchi K and Nakamura T. 2002. Inhibitory activity of brown algal phlorotannins against hy- 
aluronidase. Int J Food Sci Technol 37, 703-709.

Shibata T, Nagayama K, Tanaka R, Yamaguchi K and Nakamura T. 2003. Inhibitory effects of brown algal phlorotannins on secretory phospholipase $\mathrm{A}_{2} \mathrm{~s}$, lipoxygenases and cyclooxygenases. J Appl Phycol 15, 61-66.

Syu WJ, Shen CC, Lu JJ, Lee GH Sun CM. 2004. Antimicrobial and cytotoxic activities of neolignans from Magnolia officinalis. Chem Biodivers 1, 530-537.

Totsuka K, Shiseki M, Kikuchi K and Matsui Y. 1999. Combined effects of vancomycin and imipenem against methicillin-resistant Staphylococcus aureus (MRSA) in vitro and in vivo. J Antimicrob Chemother 44, 455-460. 